\title{
A Comparative Study of Pioneer Entry Decisions in the United States and China*
}

\author{
Y. Lisa Zhao, Michael Song, and Mark E. Parry
}

According to the resource-based view of the firm, competitive advantages arise from control and deployment of productive resources that are rare and difficult to imitate. Through early entry, pioneers can gain preferential access to key resources. However, the value of that access depends on the presence of isolating mechanisms that limit or prevent competitive imitation. Isolating mechanisms increase the desirability of early entry by lengthening the time horizon over which the firm can earn Ricardian rents on those resources. To explore these implications of the resource-based view, this study examines the impact of isolating mechanisms on pioneer advantages by analyzing the market entry timing decisions of 209 U.S. and 302 Chinese entrepreneurs. We hypothesize that the stronger intellectual property and legal protections available in the United States are an isolating mechanism that should increase the perceived importance of differentiation and cost advantages in the United States relative to China. Consistent with this argument, we find evidence that the relationships between the number of successful first-mover decisions and (1) perceived pioneer differentiation advantages and (2) perceived cost advantages are relatively stronger in the United States than in China. We also argue that the importance of personal relationships in China constitutes an isolating mechanism that should increase the perceived importance of preemptive pioneer advantages in China relative to the United States. Consistent with this reasoning, we find that the coefficient linking perceptions of pioneer preemptive advantages with the number of successful first-mover decisions is significant in the Chinese sample and not in the U.S. sample, but the difference between these coefficients is not significant. These results provide support for the argument that the availability of strong IP and legal protection encourages early entry decisions by entrepreneurs because these protections enhance the pioneer's ability to build a differentiated position in the minds of target customers and secure a cost advantage over later entrants. The results also support the argument that strong personal connections and the practice of reciprocity play a key role in the success of Chinese entrepreneurs.

\section{Introduction}

A ccording to the resource-based view of the firm, competitive advantages arise from control and deployment of productive resources that are rare and difficult to imitate (Barney, 1991; Conner, 1991; Mahoney and Pandian, 1992; Peteraf, 1993; Wernerfelt, 1984). In this paper, we examine the relationship between pioneer entry and isolating mechanisms, which are barriers to competitive imitation of productive resources. Through early entry, pioneers can gain preferential access to key resources. However, the value of that access depends on the presence of isolating mechanisms that limit or prevent competitive imitation (Mahoney and Pandian, 1992; Rumelt, 1984). Isolating mechanisms

Address correspondence to: Y. Lisa Zhao, Henry W. Bloch School of Management, University of Missouri-Kansas City, 5110 Cherry Street, Kansas City, Missouri 64110-2499. E-mail: zhaol@umkc.edu. Tel: 816235-5153.

* This research was funded in part by the China Natural Science Foundation (Award \#70528002). increase the desirability of early entry by lengthening the time horizon over which the firm can earn Ricardian rents on those resources (Mahoney and Pandian, 1992; Peteraf, 1993). However, in the absence of such isolating mechanisms, the same resources may provide a much weaker incentive for early entry.

To illustrate, consider the theoretical argument that consumer information asymmetries can be an incentive for early entry (e.g., Lieberman and Montgomery, 1988). The extent of this advantage depends in part on the presence of legal protections that prevent later entrants from copying the firm's trademarks and other brand assets. If the firm's ability to defend these brand assets is limited, it will perceive less value in consumer information asymmetries that benefit early entrants. In the same vein, difficulties in protecting intellectual property (IP) should reduce the perceived value of first-mover cost advantages based on firm-specific knowledge.

To explore these implications of the resource-based view, we examine the market entry timing decisions of U.S. and Chinese entrepreneurs. These two countries 
provide a unique context for examining the impact of cross-cultural variations in isolating mechanisms because U.S. and Chinese entrepreneurs operate within cultural and economic environments that differ significantly. Relative to their role in the United States, personal relationships have an important influence on Chinese busi-

\section{BIOGRAPHICAL SKETCHES}

Dr. Y. Lisa Zhao is an associate professor of entrepreneurship and innovation at the Regnier Institute for Entrepreneurship and Innovation, University of Missouri-Kansas City. She received her Ph.D. from Cornell University. Her scholarship revolves around new venture first product development, new venture funding and exit strategies, innovation management, market-entry decisions, and statistical methods. Her research articles appear in academic journals such as Strategic Management Journal, Journal of Operations Management, Journal of Management, Entrepreneurship Theory and Practice, Decision Sciences Journal, Journal of Product Innovation Management, and IEEE Transactions on Engineering Management.

Dr. Michael Song holds the Charles N. Kimball, MRI/Missouri Endowed Chair in Management of Technology and Innovation and is Director of the Reginer Institute for Entrepreneurship and Innovation at the University of Missouri-Kansas City (UMKC). Dr. Song also serves as a Specially Appointed Professor of Management at Harbin Institute of Technology in China and Scientific Advisor to the Institute for Governance Studies at University of Twente, the Netherlands. He received an M.S. from Cornell University and an MBA and Ph.D. from University of Virginia. He is ranked as the World's \#1 Innovation Management Scholar by Journal of Product Innovation Management in 2007 and 2012, one of the top 20 technology management scholars by R\&D Management in 2006, one of the most prolific researchers in technology innovation management field by the International Association of Technology Management in 2004 and in 2008, and among the "Most-Cited Scientists in Economics \& Business" over a 10-year period by Essential Science Indicators. He received the 2005 Excellence in Research Award from the American Marketing Association. Dr. Song is associate editor of six academic journals and serves on the editorial board of several top academic journals. Dr. Song has published over 100 articles in academic journals including Management Science, Strategic Management Journal, Academy of Management Journal, Journal of Marketing Research, Marketing Science, Journal of Marketing, Journal of the Academy of Marketing Science, Journal of International Business Studies, Journal of Operations Management, Journal of Product Innovation Management, and others.

Dr. Mark Parry holds the Ewing Marion Kauffman/Missouri Endowed Chair in Entrepreneurial Leadership at the Regnier Institute for Entrepreneurship and Innovation and is professor of marketing at the Bloch School, University of Missouri-Kansas City. His research has won several awards, including the 2005 Excellence in Global Marketing Research Award from the American Marketing Association for an article coauthored with Michael Song. His current research interests include innovation strategy, opportunity assessment, new product adoption, radical innovation, and technology entrepreneurship. His articles have appeared in a variety of academic journals, including Management Science, Academy of Management Journal, Journal of Marketing Research, Marketing Science, Journal of Marketing, Journal of the Academy of Marketing Science, Journal of Retailing, Journal of Operations Management, Journal of Product Innovation Management, Marketing Letters, and IEEE Transactions on Engineering Management. ness transactions (Luo, 2003; Park and Luo, 2001). Because personal connections can enable first entrants to gain preferential access to resources, we argue that perceived pioneer preemptive advantages will have a greater impact on pioneer entry decisions in China than in the United States. In contrast, inadequate legal protections, combined with underdeveloped legal institutions, constrain the opportunities for Chinese entrepreneurs to protect their IP (Luo, 2003; Nee, 1992; Peng and Heath, 1996). For this reason, perceived pioneer product differentiation and cost advantages should have a relatively greater impact on pioneer entry decisions in the United States.

Our analysis is based on data collected from 209 U.S. entrepreneurs and 302 Chinese service entrepreneurs. Our initial survey questioned these entrepreneurs about the relative importance of pioneer advantages and disadvantages. A second survey administered four years after the first asked the same entrepreneurs to provide information about their pioneer entry decisions since the first survey and the success of those decisions. In our data analysis, we use the negative binomial regression model to explore the relationship between the number of pioneer entry decisions made by these entrepreneurs and their earlier assessments of pioneer advantages and disadvantages.

Our results indicate that, in both China and the United States, the number of successful first-mover decisions is strongly tied to perceptions that pioneer firms experience lower costs relative to later entrants. In addition, in the United States (but not in China), the number of successful pioneer entry decisions is positively related to entrepreneurial perceptions that pioneer products are perceived by customers as more differentiated than products introduced by later entrants. Consistent with the argument that the isolating mechanisms protecting IP are stronger in the United States than in China, we find that the relationships between the number of successful first-mover decisions and (1) perceived pioneer differentiation advantages and (2) perceived cost advantages are stronger in the United States than in China. Finally, in China (but not in the United States), the number of successful pioneer entry decisions is positively related to entrepreneurial perceptions that pioneer entrants can preempt scarce resources. This result is consistent with the argument that perceived pioneer preemptive advantages will have a greater impact on pioneer entry decisions in China than in the United States. However, despite the insignificance of the relationship between preemptive advantages and successful entry in the United States, the difference between the two samples is not significant. 
Our research is important for several reasons. First, our results provide support for the argument that the availability of strong IP and legal protection encourages early entry decisions by entrepreneurs because these protections enhances the pioneer's ability to build a differentiated position in the minds of target customers and secure a cost advantage over later entrants. Second, although the perception of pioneer cost advantages has no greater impact (relative to Chinese entrepreneurs) on the number of ventures started by U.S. entrepreneurs, this perception does have a greater impact on the number of successful ventures started by U.S. entrepreneurs (relative to Chinese entrepreneurs). This result provides support for the argument that strong IP and legal protection increases the probability that entrepreneurs can translate a cost advantage into new venture success. Third, our results show that perceptions of preemptive advantages are associated with successful entrepreneurial entry in China, which is consistent with the argument that strong personal connections and the practice of reciprocity play a key role in the success of Chinese entrepreneurs. Fourth, contrary to existing research (Song, Di Benedetto, and Song, 2000), our results provide strong evidence that the entry decisions of U.S. service entrepreneurs are not influenced by the perceived importance of preemptive advantages, but are influenced by the perceived importance of cost and differentiation advantages.

\section{Literature Review}

\section{Pioneer Entry and Sustainable Competitive Advantage}

Resources are "strengths that firms can use to conceive of and implement their strategies" (Barney, 1991, p. 101). Commonly cited examples include assets and processes, as well as information, knowledge, and capabilities. According to the resource-based view of the firm, competitive advantage arises from control of productive resources that are rare, difficult to imitate, and lack effective substitutes (Barney, 1991; Conner, 1991; Lieberman and Montgomery, 1998; Wernerfelt, 1984). The control and deployment of productive resources can lead to economic rent in the presence of isolating mechanisms that limit the ability of competitors to acquire, copy, or create substitutes for those resources (Barney, 1991; Dierickx and Cool, 1989; Rumelt, 1984). These mechanisms may arise from government intervention (e.g., patents and trademarks) or from bounded rationality and causal ambiguity (Lippman and Rumelt, 1982; Mahoney and Pandian, 1992; Williamson, 1979).
The resource-based view has several important implications for studies of market entry timing. Early discussions of the resource-based view linked first-mover advantages to the control of rare and hard-to-copy resources. For example, Wernerfelt (1984) tied the success of early entrants to preferential access to resources that resulted in cost advantages over later entrants: "What a firm wants is to create a situation where its own resource position directly or indirectly makes it more difficult for others to catch up" (Wernerfelt, 1984, p. 173). Consistent with this reasoning, Barney (1991) argued that a necessary condition for a first-mover advantage is greater control, relative to later entrants, over one or more key resources. This condition can lead to a sustained competitive advantage when the controlled resources are (1) integral to the firm's strategy and (2) difficult for later entrants to access, duplicate, or replace with resources of comparable efficiency (Barney, 1991; see also Barney, Wright, and Ketchen, 2001; Conner, 1991; Peteraf, 1993).

A second important implication involves the use of early market entry as a strategy for acquiring control over unique and hard-to-copy resources. For example, early entrants may benefit from control of key inputs, production processes, and marketing resources (Lieberman and Montgomery, 1988). Early entrants may also acquire proprietary knowledge about technology and production processes. In addition, consumers sometimes perceived products differently based on their order of market entry. Carpenter and Nakamoto (1989) argued that the attribute profile of pioneer products can influence consumer perceptions of the ideal product profile (see also Alpert and Kamins, 1994). Moreover, switching costs, which arise when customers make nontransferable investments in learning to use pioneer products, can discourage consumers from switching to a product introduced by later entrants (Fornell, Robinson, and Wernerfelt, 1985; Lieberman and Montgomery 1988).

Importantly, the value of resources and capabilities acquired through early entry depends on the presence of isolating mechanisms that prevent the diffusion of those resources and capabilities to later entrants (Mahoney and Pandian, 1992). When isolating mechanisms inhibit competitive imitation of a key resource, the firm benefits from control of that resource even after competitors enter the market. However, in the absence of such isolating mechanisms, competitive entry reduces the firm's return on that resource. As a result, the absence of isolating mechanisms reduces the firm's incentive to try and acquire control of key resources through early market entry. 
For example, existing research argues that the opportunity to acquire a technological leadership position can be an incentive for early entry (Lieberman and Montgomery, 1988). The extent of this advantage depends in part on the presence of an effective patent system that creates barriers to imitation (Mahoney and Pandian, 1992). More generally, weak IP legislation, or lax enforcement of IP legislation, should weaken the potential benefits of technological and consumer information asymmetries that benefit early entrants.

In their study of the microcomputer and PC industries, Schoenecker and Cooper (1998) provide indirect support for this argument. In the minicomputer industry, where entry barriers were significant, research and development (R\&D) intensity and possession of a direct force had significant negative effects on order of entry. In contrast, in the PC industry, where entry barriers were much lower, order of entry was unrelated to the possession of a direct sales force and positively related to R\&D intensity. In part, the presence of entry barriers in the microcomputer industry reflected the impact of isolating mechanisms that made it difficult for potential entrants to acquire the resources needed for market entry. Unfortunately, the study does not specifically assess the nature of those isolating mechanisms and the relationship between resources and entry timing. Thus our goal in this paper is to provide a direct test of the argument that isolating mechanisms influence marketing timing decisions.

\section{Cross-Country Comparisons of Pioneer Advantages}

In their seminal cross-country study of first-mover advantages, Song, Di Benedetto, and Zhao (1999) examined the perceived importance of a variety of mechanisms that have been hypothesized to create advantages for pioneers. From a literature review, the authors created a pool of items designed to measure a series of pioneer advantages and disadvantages. The list of items was refined through field interviews and pretests with both academic and business experts. In their empirical analysis, the authors compared the mean responses of service- and manufacturer-firm managers from nine countries, including the United States and China, on 54 pioneer advantage items that were grouped into four categories: performance advantages, differentiation advantages, cost advantages, and post-entry risk. With regard to differentiation advantages, the authors concluded that U.S. service-firm managers perceived pioneers to have three different advantages (brand image, product quality, and price premium), while Chinese service-firm managers did not perceive any of these advantages to be important.
With regard to cost advantages, U.S. service-firm managers perceived pioneers to have five different cost advantages, while Chinese service-firm managers perceived only one (a superior labor force) to be important.

A companion study (Song et al. 2000) focused on managers responsible for new service development and grouped the pioneer advantage items into five categories: performance, economic advantages, preemptive advantages, technological advantages, and behavioral advantages. None of the economic advantages were perceived as significant by U.S. managers, and only one (learning curve effects) was perceived as significant by Chinese managers. The ability to preempt superior labor was perceived as important by both U.S. and Chinese managers. In addition, U.S. managers perceived pioneers to enjoy lower production costs and preempt higher quality raw materials, while Chinese managers perceived pioneers to have the ability to preempt equipment and location. Finally, U.S. managers did not perceive any of the hypothesized behavioral pioneering advantages to be important, while Chinese managers believed that first entrants could benefit from the costs customers would incur by switching from a pioneer product to that of a later entrant.

Both of these studies provide important insights into variations between countries in the average importance ascribed to different pioneer advantage mechanisms. The current paper seeks to extend this research by (1) examining the variations within a country (the United States or China) in the impact of pioneer advantage perceptions on the actual market entry decisions of service firms and (2) comparing the strength of this impact in the United States and China. To address these two points, in the next section, we develop hypotheses about the relative strength of the advantage-entry relationship in these two countries for three kinds of pioneer advantage: preemptive advantages, differentiation advantages, and cost advantages.

\section{Research Hypotheses}

In this section, we examine three first-mover advantages discussed in the pioneer entry literature. We argue that the impact of entrepreneurial perceptions of these advantages on the entry decisions of U.S. and Chinese service entrepreneurs should reflect the degree to which idiosyncratic characteristics of U.S. and Chinese markets affect the effectiveness of important isolating mechanisms. In particular, we argue that the link between perceived pioneer advantages and actual entry decisions will reflect the importance of personal connections in Chinese business 
(Luo, 2003; Park and Luo, 2001; Zhao and Parry, 2012) and the presence of underdeveloped legal institutions and inadequate legal protections (Luo, 2003; Nee, 1992; Peng and Heath, 1996). In light of these considerations, we hypothesize that the impact on entry behavior of perceived preemptive advantages will be relatively greater in China, while the impact of perceived pioneer differentiation and cost advantages will be relatively greater in the United States.

\section{Preemptive Advantages}

Preemptive advantages refer to the pioneer's ability to gain preferential access to or control over resources that are critical to venture success (Lieberman and Montgomery, 1988). In some markets, pioneers can acquire the most productive variants of resources that are vital for venture success, leaving less productive resources for later entrants. In other cases, pioneers can obtain key resources on more favorable terms than later entrants (Wernerfelt, 1984). The result in either case is higher costs for later entrants, and in some cases, the cost disadvantage can lead potential competitors to forego entry. In addition to the preemption of resources needed for the production of goods and services, pioneers may also secure preferential access to geographic or distribution space, which is known as spatial preemption. For example, the first firm to introduce a new product can sometimes obtain distribution through more attractive marketing channels and secure a larger number of shelffacings relative to later entrants (Kerin, Varadarajan, and Peterson, 1992). For service entrepreneurs, one of the most important forms of spatial preemption is the ability to acquire premier locations that are likely to generate the most customer traffic, leaving the less desirable locations for later entrants (Lieberman and Montgomery, 1988).

One important dimension of asset preemption for Chinese firms involves guanxi, which refers to the importance of personal connections and the practice of reciprocity (Fung, Xu, and Zhang, 2007; Li, Poppo, and Zhou, 2008; Lockett, 1988; Park and Luo, 2001). Entrepreneurial firms that operate without the institutional connections of state-owned firms often rely on personal relationships to access needed resources and drive revenue growth (Xin and Pearce, 1996). Fung et al. (2007) attributed the high entertainment expenditures reported by privately held entrepreneurial firms to the importance of establishing and cultivating relationships with suppliers, customers, and other key stakeholders. In part, the emphasis on networking among Chinese entre- preneurs reflects the continued importance of the state in China's transitional economy. As Luo (2003) explained:

\section{Economic transition generates preemptive opportunities that can be transformed into economic returns. Network- ing through personal ties is a necessary step for obtain- ing these opportunities because opportunities are largely controlled by government officials in power or executives at other firms on which the focal firm depends. (p. 1317)}

Timing of market entry influences the ability of Chinese entrepreneurs to establish and nurture relationships that provide preferential access to critical resources and create barriers to entry by placing later entrants at a cost disadvantage. Relative to U.S. business practices, the heightened value placed on interpersonal connections in Chinese business practices should strengthen the perceived impact of asset preemption advantages among Chinese entrepreneurs and lead to more first-mover decisions (Zhao and Parry, 2012). Thus we hypothesize that:

H1: Variations in the perceived importance of pioneer
preemptive advantages will have a stronger influence on
the number of first-mover decisions among Chinese
service entrepreneurs than among U.S. service
entrepreneurs.

\section{Differentiation Advantages}

First-mover advantages often arise from differences in the ways consumers perceive pioneer firms relative to later entrants. For example, relative to later entrants, many successful pioneer products are perceived to have more appealing design characteristics and higher quality (Robinson and Fornell, 1985). In part, these perceptions may reflect the impact of information asymmetry. Because the pioneer product has been on the market longer than later entrants, consumers have had more opportunities to learn about the pioneer's products (Robinson and Fornell, 1985; Schmalensee, 1982). In addition, early entrants have the opportunity to influence customer perceptions of the desired levels of subjective product attributes (Alpert and Kamins, 1994; Carpenter and Nakamoto, 1989; Fornell et al., 1985; Urban, Carter, Gaskin, and Mucha, 1986). The pioneer who can successfully define customer preferences places pressure on followers to imitate the pioneer's products and thus limits their opportunities for product differentiation (Kalyanaram, Robinson, and Urban, 1995).

Successful pioneer firms often leverage their differentiation advantages in at least two ways. First, higher 
quality perceptions may enable pioneer firms to charge higher prices than later entrants (Lieberman and Montgomery, 1988; Schmalensee, 1982). Second, an established reputation for quality can create opportunities for line extensions that further differentiate the pioneer's brand from those of later entrants (Kerin et al., 1992; Lilien and Yoon, 1990; Prescott and Visscher, 1977).

The ability of Chinese entrepreneurs to create an enduring competitive advantage through differentiation is limited by the treatment of IP rights in China (Zhao and Parry, 2012). Major problems include counterfeiting, including the copying of brand logos and trademarks. While existing IP laws address some of these issues, these laws are often not enforced because "the court system is still in reform and administrative bureaus have limited authority" (Sybert, 2008, p. 12). A related problem involves the duplication of advertising images and messages, which are not covered by existing IP laws protection (Fowler, 2004). In contrast, IP provisions are stronger in the United States, and the enforcement of IP laws is less arbitrary. For this reason, relative to U.S. entrepreneurs, Chinese entrepreneurs should have more difficulty establishing a sustainably differentiated position. This reasoning suggests the following hypothesis:

H2: Variations in the perceived importance of pioneer differentiation advantages will have a stronger influence on the number of first-mover decisions among U.S. service entrepreneurs than among Chinese service entrepreneurs.

\section{Cost Advantages}

A third source of pioneer advantages involves cost differences between first movers and later entrants. In part, these cost advantages may arise from the opportunity of pioneers (given sufficient sales volume) to move down the learning curve more quickly than later entrants (Robinson, 1988; Robinson and Fornell, 1985; Spence, 1979). First movers can also benefit from economies of scale and scope. In particular, pioneers can lessen the impact of fixed costs on unit margins by (1) building and maintaining larger sales volumes than later entrants and (2) expanding product lines to leverage existing fixed cost expenditures. In addition, first movers often have lower communication costs relative to later entrants. The level of expenditures needed to educate consumers about a firm's products depends in part on the level of confusion arising from contradictory competitive claims. To the extent that pioneers have the opportunity to educate customers and build differentiated positions before competitive firms enter, pioneers may enjoy a communication cost advantage over later entrants (Comanor and Wilson, 1979). Importantly, this communication cost advantage may be offset by the ability of later entrants to free-ride on pioneer investments in product category education (Lieberman and Montgomery, 1988).

Some of these benefits are likely to be more significant in the United States than in China. As noted above, competitive imitation of advertising copy and images enables later entrants to free-ride on the advertising investments of pioneers (Fowler, 2004). Such copying lessens the effectiveness of pioneer advertising and may actually create a pioneer cost disadvantage. In addition, weak safeguards against IP will increase the difficulty of protecting proprietary knowledge underlying a pioneer's learning curve advantages. Given the stronger IP protections available to U.S. pioneers, we hypothesize that:

\section{H3: Variations in the perceived importance of pioneer cost advantages will have a stronger influence on the number of first-mover decisions among U.S. service entrepreneurs than among Chinese service entrepreneurs.}

\section{Research Design and Data Collection}

To test our hypotheses regarding the relationship between early entry decisions and perceptions of early entry advantages and disadvantages, we surveyed service entrepreneurs in the United States and China. Our data collection process consisted of two stages. In the first stage, we surveyed founders regarding their perceptions of the advantages and disadvantages of early entry. Four years later, we contacted the entrepreneurs who responded to the first survey and asked them to provide the number of early entry decisions made since the time of the first survey. Additional details on the research methodology are available in Zhao and Parry (2012) and Song, Zhao, and Di Benedetto (2013).

\section{Survey Development}

Our survey instruments were prepared based on the scale items developed and validated by Song et al. (1999). The original questionnaire was in English. A parallel/double translation procedure was used to prepare the Chinese version (Douglas and Craig, 1983). The Englishlanguage questionnaire was first translated into Chinese, after which the Chinese version was back-translated back into English by a translator with no knowledge of the 
original English version. A comparison of the two English versions revealed a few minor discrepancies between the two English versions, which led to several minor revisions to the Chinese questionnaire.

The English version of the questionnaire was pretested with 53 employees from four U.S. companies, while the Chinese version was pretested with 12 Chinese entrepreneurs. In each case, respondents were asked to identify any problems they encountered while completing the questionnaire. These pretests resulted in a few small changes to each questionnaire.

\section{Sample Definition Collection}

The U.S. sample was drawn from new independent businesses listed in the Dun \& Bradstreet corporate database (Song et al., 2013). Because of budget constraints, we randomly selected 200 founders from 200 firms in each of the following five industries: Professional, Scientific, and Technical Services (NAICS 54); Securities, Commodity Contracts, and Other Financial Investments and Related Activities (NAICS 52); Information (NAICS 51); Hotels and Casino Hotels (NAICS 72); and Administrative \& Support (NAICS 56).

For the Chinese data, we collected lists of 2421 founders of new service ventures in four Chinese cities: Guangzhou, Putian, Shanghai, and Fuzhou. The sample frame included the same five service industries included in the U.S. sample sampling frame (Zhao and Parry, 2012).

\section{Data Collection}

Our data collection process was guided by the Total Design Method for survey research (Dillman, 1978). In the United States, we mailed the survey to all 1000 founders in our initial sample, but 114 mailing packages were undelivered (because the contact person had left the company or the address was incorrect) and 91 founders declined to participate, which yielded an adjusted sample of 795 businesses. To increase the response rate, we offered periodic research reports, executive seminars, and research briefings as incentives for participation. We also sent follow-up letters/faxes and, in some cases, made multiple phone calls to the entrepreneurs who did not respond to our initial mailing. In the end, we received completed questionnaires from 334 firms, representing a response rate of $42 \%$. The breakdown of the respondents in each of the five industries is provided in Table 1.

In China, we mailed the survey to all 2421 founders in our sample frame. To encourage participation, we offered recipients an incentive of $100 \mathrm{RMB}$ (about \$14.00) to complete the survey. The initial mailing was followed by four subsequent mailings to nonrespondents. This process yielded completed surveys from 633 entrepreneurs, a response rate of $26 \%$.

To collect the number of "first-mover" decisions made by each of the founders who participated in our first data collection, we conducted a second data collection four years later. We attempted to contact the 334 U.S. founders who completed our first survey and asked each of them to provide the number of "first-mover" new service decisions he/she made since the first survey. Of the original 334 executives, 209 provided this information (Song et al., 2013), which represented $26 \%$ of the firm adjusted sample frame and $63 \%$ of the respondents who completed the first survey four years earlier.

We repeated this process with the 633 Chinese entrepreneurs who responded to our first survey. In this case,

Table 1. Industry Representation

\begin{tabular}{|c|c|c|c|c|c|}
\hline \multirow[b]{2}{*}{ Industry } & \multirow[b]{2}{*}{ Service Industry Description } & \multicolumn{2}{|c|}{ U.S. Survey } & \multicolumn{2}{|c|}{ China Survey } \\
\hline & & $\begin{array}{l}\text { Respondents to First } \\
\text { Survey }(n=334)\end{array}$ & $\begin{array}{l}\text { Respondents to Second } \\
\text { Survey }(n=209)\end{array}$ & $\begin{array}{l}\text { Respondents to First } \\
\text { Survey }(n=633)\end{array}$ & $\begin{array}{l}\text { Respondents to Second } \\
\text { Survey }(n=302)\end{array}$ \\
\hline Industry 1 & $\begin{array}{l}\text { Professional, scientific, and } \\
\text { technical services }\end{array}$ & 48 & 29 & 84 & 40 \\
\hline Industry 2 & $\begin{array}{l}\text { Securities, commodity contracts, } \\
\text { and other financial investments } \\
\text { and related activities }\end{array}$ & 86 & 49 & 146 & 75 \\
\hline Industry 3 & Information and related services & 87 & 58 & 158 & 78 \\
\hline Industry 4 & Hotels & 57 & 37 & 131 & 63 \\
\hline Industry 5 & Administrative and support & 56 & 36 & 114 & 46 \\
\hline Total & & 334 & 209 & 633 & 302 \\
\hline Response rate & & $\begin{array}{c}42 \% \text { of the original } \\
\text { sample }\end{array}$ & $\begin{array}{c}63 \% \text { of the participants } \\
\text { in the first survey }\end{array}$ & $\begin{array}{c}26 \% \text { of the original } \\
\text { sample }\end{array}$ & $\begin{array}{c}48 \% \text { of the participants } \\
\text { in the first survey }\end{array}$ \\
\hline
\end{tabular}


302 provided the requested information, representing $48 \%$ of the respondents who participated in our first data collection and $12 \%$ of the original sample (Zhao and Parry, 2012). Table 1 provides additional information about the country-specific industry representation in each survey.

\section{Independent Study Measures}

As noted above, our measures of the perceived preemptive, differentiation, and cost advantages of pioneers were taken from Song et al. (1999; also see Song et al., 2013; Zhao and Parry, 2012). The 7-point response scale used for each item ranged from 1 (very unlikely) to 7 (very likely). Preemptive Advantages contained three items that dealt with respondent beliefs about the ability of first movers to preempt service locations, distribution channels, and supplies. Differentiation Advantages comprised four items that dealt with the perceived importance of a pioneer position on customer perceptions of the firm's technical leadership, product quality, product line breadth, and brand image. Cost Advantages was measured using three statements that focused on the ability of pioneers to benefit from economies of scale, lower delivery costs, and greater absolute cost savings.

Our regressions also included several control variables. Age, defined as the chronological age of the founding entrepreneur, ranged from 22 to 58 years with a mean value of 39 years for Chinese entrepreneurs and from 22 to 57 years with a mean value of 39 years for U.S. entrepreneurs. In addition, we used dummy variables to signify four of the five industries represented in our sample.

\section{Dependent Variables}

Following Robinson (1988; see also Parry and Bass, 1990; Robinson and Fornell, 1985), we defined a first mover or pioneer as one of the first three entrants into a market. Like Song et al. (2013) and Zhao and Parry (2012), we examined two dependent variables: the first is a count of the total number of major first-mover decisions made by an entrepreneur during the four-year period of our study, while the second is a count of the total number of successful major first-mover decisions made during the same period. The validity of these dependent variables were established by (1) surveying a second founder in a subset of firms within each sample and (2) a review of the entry decisions made by 20 firms in each sample using secondary data sources. For details on these validation checks, please see Zhao and Parry (2012) and Song et al. (2013).

\section{Data Analyses and Results}

\section{Cross-Country Measurement Equivalence}

The questionnaire items for differentiation advantage, preemptive advantage, and cost advantage in our survey were developed and validated by Song et al. (1999) for conceptual and functional equivalence across nine countries. In this study, we further tested for cross-country metric equivalence using the multiple group LISREL confirmatory factor analysis procedure described by Brown (2006) and Mullen (1995). The process we followed consisted of estimating a sequence of four measurement models, where each model in the sequence contained an additional set of parameter constraints relative to the preceding model.

First, we estimated an equal form measurement model (model 1) in which both countries were assumed to have the same factor structure (the same scale items), but path coefficients (factor loadings) along with measurement item (or factor) variances and covariances were allowed to differ between the two countries. As shown in Table 2, the fit indices of this model $\left(\chi^{2}\right)$ d.f. $=2.89$; root mean square error of approximation $[\mathrm{RMSEA}]=.08$; root mean residual $[\mathrm{RMR}]=.09$; min[normed fit index (NFI), Tucker-Lewis index (TLI), comparative fit index (CFI), goodness of fit index

Table 2. Cross-Country Construct Metric Equivalence Tests on Differentiation Advantages, Preemptive Advantages, and Cost Advantages

\begin{tabular}{|c|c|c|c|c|c|c|c|c|}
\hline Measurement Invariance & $\chi^{2}$ & d.f. & RMSEA & SRMR & NFI & TLI & $\mathrm{CFI}$ & GFI \\
\hline Model 1-Equal form & 184.96 & 64 & .08 & .09 & .90 & .90 & .93 & .91 \\
\hline Model 2-Equal factor loadings & 199.32 & 71 & .08 & .09 & .89 & .91 & .93 & .90 \\
\hline Model 3-Equal indicator intercepts & 228.77 & 81 & .09 & .09 & .88 & .91 & .92 & .90 \\
\hline Model 4-Equal error variances & 296.84 & 91 & .10 & .11 & .84 & .89 & .88 & .86 \\
\hline
\end{tabular}

United States: $n=209$; China: $n=302$. 
Table 3. Means, Correlation Coefficients, and Construct Reliabilities

\begin{tabular}{|c|c|c|c|c|c|c|}
\hline & DIFF & PREE & COST & AGE & NFIRST & NSUCC \\
\hline \multicolumn{7}{|l|}{ U.S. Sample $(n=209)$} \\
\hline Differentiation advantages (DIFF) & 1.00 & -.04 & -.03 & .00 & .25 & .25 \\
\hline Preemptive advantages (PREE) & & 1.00 & .07 & .00 & .11 & .14 \\
\hline Cost advantages (COST) & & & 1.00 & .05 & .22 & .28 \\
\hline Age & & & & 1.00 & .02 & .01 \\
\hline Number of first decisions (NFIRST) & & & & & 1.00 & .87 \\
\hline Number of successful decisions (NSUCC) & & & & & & 1.00 \\
\hline Mean & 3.26 & 4.73 & 3.62 & 38.60 & .89 & .46 \\
\hline Standard deviation & .94 & 1.39 & 1.59 & 10.22 & 1.59 & 1.17 \\
\hline Construct reliability—Cronbach's alpha & .71 & .81 & .78 & & & \\
\hline \multicolumn{7}{|l|}{ China Sample $(n=302)$} \\
\hline Differentiation advantages (DIFF) & 1.00 & -.01 & -.09 & .06 & -.01 & .05 \\
\hline Preemptive advantages (PREE) & & 1.00 & -.16 & -.06 & .11 & .08 \\
\hline Cost advantages (COST) & & & 1.00 & -.06 & .13 & .10 \\
\hline Age & & & & 1.00 & .00 & .01 \\
\hline Number of first decisions (NFIRST) & & & & & 1.00 & .94 \\
\hline Mean & 3.42 & 4.30 & 3.54 & 39.08 & 1.64 & .91 \\
\hline Standard deviation & 1.24 & 1.41 & 1.62 & 10.18 & 2.20 & 1.47 \\
\hline Construct reliability —Cronbach's alpha & .82 & .75 & .77 & & & \\
\hline
\end{tabular}

$(\mathrm{GFI})] \geq .90)$ are all above conventional standards for acceptable fit (Brown, 2006; Hu and Bentler, 1999).

Second, we estimated a second measurement model (model 2) by incorporating an additional set of constraints: we forced the path coefficients to be the same for both countries (while continuing to permit variances and covariances to vary across countries). The difference in total $\chi^{2}$ values between model 1 and model 2 is $14.36\left(\chi^{2} /\right.$ d.f. $=$ 2.05). The $\chi^{2}$ value and differences of the fit statistics between model 2 and model 1 suggest that the two countries have the same factor structure and the same factor loadings (Brown, 2006; Cheung and Rensvold, 2002).

Next, following Cheung and Rensvold (2002), we estimated a third model (model 3) that forced identical measurement model intercepts in both countries. The fit indices for model 3 indicate that this model fits the data as well as models 1 and 2. Based on a comparison of models $1-3$, we conclude that our measurement model demonstrates strong construct invariance (Cheung and Rensvold, 2002). Finally, we estimated a fourth model (model 4) that constrains the error variances to be the same across the two countries. Relative to models $1-3$, model 4 does not fit the data well. For this reason, we were unable to establish the strictest form of structural equivalence. However, this hurdle is rarely overcome in cross-cultural empirical studies. As Brown (2006) points out, "most methodologists regard equality of error variances and covariances to be an overly restrictive test that is usually not important to the endeavor of measurement invariance evaluation" (p. 260).
Based on the results of our confirmatory factor analysis, new variables were computed for each construct by averaging the ratings of the items assigned to that construct. The basic statistics and construct reliabilities for these "averaged variables" are reported in Table 3. As reported in this table, the reliabilities of these variables all exceed the .70 threshold recommended by Peter (1979).

\section{Pioneer Advantage Perceptions and the Total Number of Entry Decisions}

Our dependent variables are counts of the number of successful first-mover decisions and the number of total first-mover decisions. A univariate analysis revealed significant dispersion in these counts, along with many zero values. Among Chinese entrepreneurs, 50\% of them made zero successful first-mover decisions and $37 \%$ of them made zero first-mover decisions. Among U.S. entrepreneurs, $75 \%$ of them made zero successful first-mover decisions and $60 \%$ of them made zero first-mover decisions. Because the variances of these variables were larger than the means, we tested our hypotheses with a series of negative binomial regression models. (For a summary of key aspects of the negative binomial model, see Zhao and Parry, 2012.) Model estimates are summarized in Tables 4 and 5. Following Zhao and Parry (2012), research hypotheses were evaluated at the 5\% level of confidence. To simplify our discussion of these hypotheses, we begin with a discussion of the number of pioneer entry decisions. 
Table 4. Parameter Estimates from Negative Binomial Regression with Dependent Variable "Number of First-Mover Decisions"

\begin{tabular}{|c|c|c|c|c|c|c|}
\hline & \multicolumn{2}{|c|}{ Model 1} & \multicolumn{2}{|c|}{ Model 2} & \multicolumn{2}{|c|}{ Model 3} \\
\hline & Coefficient & S.E. & Coefficient & S.E. & Coefficient & S.E. \\
\hline Intercept & -0.05 & 0.30 & $-1.67 * * *$ & 0.44 & $-2.83 * * *$ & 0.64 \\
\hline Differentiation advantages (DIFF, $\left.\beta_{\mathrm{DIF}}^{\mathrm{US}}\right)^{\mathrm{a}}$ & & & $0.11 * *$ & 0.06 & $0.51 * * *$ & 0.12 \\
\hline Preemptive advantages $\left(\text { PREE, } \beta_{\mathrm{PRE}}^{\mathrm{US}}\right)^{\mathrm{a}}$ & & & $0.14 * * *$ & 0.05 & 0.08 & 0.08 \\
\hline Cost advantages $\left(\text { COST, } \beta_{\mathrm{COST}}^{\mathrm{US}}\right)^{\mathrm{a}}$ & & & $0.15^{* * *}$ & 0.04 & $0.18 * * *$ & 0.07 \\
\hline China dummy $\left(\beta_{\mathrm{DUM}}^{\mathrm{CH}}\right)$ & $0.61 * * *$ & 0.13 & $0.71 * * *$ & 0.13 & $2.32 * * *$ & 0.74 \\
\hline Country $\cdot \operatorname{DIFF}\left(\beta_{\mathrm{DIF}}^{\mathrm{INT}}\right)^{\mathbf{b}}$ & & & & & $-0.51 * * *$ & 0.14 \\
\hline Country $\cdot$ PREE $\left(\beta_{\mathrm{PRE}}^{\mathrm{INT}}\right)^{\mathbf{b}}$ & & & & & 0.08 & 0.10 \\
\hline Country $\cdot \operatorname{COST}\left(\beta_{\mathrm{COST}}^{\mathrm{INT}}\right)^{\mathbf{b}}$ & & & & & -0.05 & 0.08 \\
\hline Professional services $^{\mathrm{c}}$ dummy variable & -0.13 & 0.23 & -0.10 & 0.23 & -0.18 & 0.23 \\
\hline Financial services dummy variable & 0.13 & 0.20 & 0.12 & 0.19 & 0.01 & 0.20 \\
\hline Information services dummy variable & -0.20 & 0.20 & -0.18 & 0.20 & -0.28 & 0.20 \\
\hline Hospitality services dummy variable & -0.33 & 0.21 & -0.24 & 0.21 & -0.33 & 0.21 \\
\hline Age & 0.00 & 0.01 & 0.00 & 0.01 & 0.00 & 0.01 \\
\hline Dispersion & 1.22 & 0.15 & 1.08 & 0.14 & 1.01 & 0.14 \\
\hline
\end{tabular}

Notes:

a The main effect regression coefficients (i.e., the coefficients measuring the impact of pioneering advantages on first-mover decisions) apply to U.S. entrepreneurs.

b The interactions are the differences between the coefficients for the United States and China; the main effect regression coefficients for Chinese entrepreneurs are computed from the U.S. main effects and the corresponding interaction terms.

${ }^{\mathrm{c}}$ Professional services include professional, scientific, and technical services; financial services include securities, commodity contracts, and other financial investment and related services; information services include information and related services; and hospitality services include hotels and hotel-related services. The baseline industry in the model is administrative services, which includes administrative and support services.

$* * * p<.01 ; * * p<.05$.

In Table 4, the dependent variable is the number of first-mover decisions. Model 1 contains the five industry dummy variables and firm age. None of these control variables is significant. However, the country dummy variable is positive and significant $\left(\beta_{\mathrm{DUM}}^{\mathrm{CH}}=.61, p<.01\right)$. Thus the number of first-mover decisions was significantly higher among Chinese entrepreneurs relative to U.S. entrepreneurs. Model 2 adds the three pioneer advantage variables that are the focus of our hypotheses. The number of pioneer entry decisions was positively associated with perceptions of pioneer preemptive advantages $\left(\beta_{\mathrm{PRE}}^{\mathrm{US}}=.14, p<.01\right)$, differentiation advantages $\left(\beta_{\mathrm{DIF}}^{\mathrm{US}}=.11, p<.05\right)$, and cost advantages $\left(\beta_{\mathrm{COST}}^{\mathrm{US}}=.15\right.$, $p<.01)$.

Model 3 includes interaction terms that were computed by multiplying the country dummy variable by the pioneer advantage variables. Because the country dummy variable is defined so that a "1" signifies China, the main effects represent the regression coefficients in the U.S. model, while the interaction terms represent the differences in the Chinese and U.S. regression coefficients.

Table 6 summarizes the pioneer advantage coefficients for each country and tests the significance of the betweencountry difference in each coefficient. Focusing first on the U.S. model, the number of first-mover decisions has a positive and significant relationship with two of the pioneer advantage variables: differentiation advantages $\left(\beta_{\mathrm{DIF}}^{\mathrm{US}}=.51, p<.01\right)$ and cost advantages $\left(\beta_{\mathrm{COST}}^{\mathrm{US}}=.18\right.$, $p<.01)$. Moreover, the difference between the magnitude of the differentiation and cost coefficients $\left(\beta_{\mathrm{DIF}}^{\mathrm{US}}-\beta_{\mathrm{COST}}^{\mathrm{US}}\right)$ is statistically significant $\left(\chi^{2}=5.56, p<.05\right)$. In contrast, the coefficient of preemptive advantages is insignificant ( $\left.\beta_{\mathrm{PRE}}^{\mathrm{US}}=.08, p>.10\right)$. Thus perceptions of preemptive advantage are not related to the first-mover decisions of U.S. entrepreneurs. However, the difference between the magnitudes of the cost and preemptive advantage coefficients $\left(\beta_{\mathrm{COST}}^{\mathrm{US}}-\beta_{\mathrm{PRE}}^{\mathrm{US}}\right)$ is not significant $\left(\chi^{2}=.82\right.$, $p>.05)$.

The regression coefficients for Chinese entrepreneurs are the sum of the corresponding regression coefficients for U.S. entrepreneurs and the interaction terms. The results of these computations are contained in Table 6 . Because the differentiation advantage regression coefficient for China is statistically indistinguishable from zero $\left(\beta_{\mathrm{DIF}}^{\mathrm{CH}}=\beta_{\mathrm{DIF}}^{\mathrm{US}}+\beta_{\mathrm{DIF}}^{\mathrm{INT}}, p>.10\right)$, we conclude that perceptions of differentiation advantage are not related to the number of first-mover decisions of Chinese entrepreneurs. In contrast, perceptions of cost advantages $\left(\beta_{\mathrm{COST}}^{\mathrm{CH}}=\beta_{\mathrm{COST}}^{\mathrm{US}}+\beta_{\mathrm{COST}}^{\mathrm{INT}}=.13, p<.01\right)$ and preemptive 
Table 5. Parameter Estimates from Negative Binomial Regression with Dependent Variable "Number of Successful First-Mover Decisions"

\begin{tabular}{|c|c|c|c|c|c|c|}
\hline & \multicolumn{2}{|c|}{ Model 1} & \multicolumn{2}{|c|}{ Model 2} & \multicolumn{2}{|c|}{ Model 3} \\
\hline & Coefficient & s.e. & Coefficient & s.e. & Coefficient & s.e. \\
\hline Intercept & $-0.86 * *$ & 0.35 & $-2.80 * * *$ & 0.54 & $-5.45 * * *$ & 0.87 \\
\hline Differentiation advantages (DIFF, $\left.\beta_{\mathrm{DIF}}^{\mathrm{US}}\right)^{\mathrm{a}}$ & & & 0.10 & 0.06 & $0.74 * * *$ & 0.17 \\
\hline Preemptive advantages (PREE, $\left.\beta_{\mathrm{PRE}}^{\mathrm{US}}\right)^{\mathrm{a}}$ & & & $0.16^{* * *}$ & 0.06 & 0.12 & 0.10 \\
\hline Cost advantages $\left(\mathrm{COST}, \beta_{\mathrm{COST}}^{\mathrm{US}}\right)^{\mathrm{a}}$ & & & $0.19 * * *$ & 0.05 & $0.32 * * *$ & 0.09 \\
\hline China dummy $\left(\beta_{\mathrm{DUM}}^{\mathrm{CH}}\right)$ & $0.70 * * *$ & 0.16 & $0.87 * * *$ & 0.16 & $4.45 * * *$ & 0.95 \\
\hline Country $\cdot \operatorname{DIFF}\left(\beta_{\mathrm{DIF}}^{\mathrm{INT}}\right)^{\mathbf{b}}$ & & & & & $-0.80 * * *$ & 0.18 \\
\hline Country $\cdot$ PREE $\left(\beta_{\mathrm{PRE}}^{\mathrm{NIT}}\right)^{\mathrm{b}}$ & & & & & 0.02 & 0.12 \\
\hline Country $\cdot \operatorname{COST}\left(\beta_{\mathrm{COST}}^{\mathrm{INT}}\right)^{\mathbf{b}}$ & & & & & $-0.22 * *$ & 0.10 \\
\hline Professional services $^{\mathrm{c}}$ dummy variable & -0.09 & 0.28 & 0.00 & 0.28 & -0.08 & 0.27 \\
\hline Financial services dummy variable & $0.41 *$ & 0.23 & $0.41 * *$ & 0.23 & 0.23 & 0.23 \\
\hline Information services dummy variable & -0.14 & 0.24 & -0.09 & 0.23 & -0.22 & 0.23 \\
\hline Hospitality services dummy variable & -0.33 & 0.26 & -0.20 & 0.26 & -0.33 & 0.25 \\
\hline Age & 0.00 & 0.01 & 0.00 & 0.01 & 0.00 & 0.01 \\
\hline Dispersion & 1.34 & 0.21 & 1.13 & 0.19 & 0.98 & 0.18 \\
\hline Log likelihood (Model degree of freedom) & \multicolumn{2}{|c|}{$-387.45(504)$} & \multicolumn{2}{|c|}{$-373.85(501)$} & \multicolumn{2}{|c|}{$-360.80(498)$} \\
\hline
\end{tabular}

${ }^{a}$ The main effect regression coefficients (i.e., the coefficients measuring the impact of pioneering advantages on first-mover decisions) apply to U.S. entrepreneurs.

${ }^{\mathrm{b}}$ The interactions are the differences between the coefficients for the United States and China; the main effect regression coefficients for Chinese entrepreneurs are computed from the U.S. main effects and the corresponding interaction terms.

${ }^{c}$ Professional services include professional, scientific, and technical services; financial services include securities, commodity contracts, and other financial investment and related services; information services include information and related services; and hospitality services include hotels and hotel-related services. The baseline industry in the model is administrative services, which includes administrative and support services.

$* * * p<.01 ; * * p<.05$.

advantage $\left(\beta_{\mathrm{PRE}}^{\mathrm{CH}}=\beta_{\mathrm{PRE}}^{\mathrm{US}}+\beta_{\mathrm{PRE}}^{\mathrm{INT}}=.15, p<.01\right)$ are positive and significantly different from zero.

In addition to affecting the direct effects of first-mover advantages on the market entry decisions of Chinese entrepreneurs, the interaction terms also enable us to directly test our hypotheses about the relative impact of different first-mover advantages on the entry decisions of U.S. and Chinese entrepreneurs. The signs of all three interaction terms are consistent with our hypotheses, but only one is significant. In particular, the coefficient of China Dummy $\times$ Differentiation is negative and significantly different from zero $\left(\beta_{\mathrm{DIF}}^{\mathrm{INT}}=-.51, p<.01\right)$. Thus, of

Table 6. Hypothesis Testing Summary

Dependent Variable: Number of First-Mover Decisions

\begin{tabular}{|c|c|c|c|}
\hline & U.S. & China & $\begin{array}{c}\text { Country Difference } \\
\text { U.S.-China }\end{array}$ \\
\hline H1: Preemptive advantages & $\beta_{\mathrm{PRE}}^{\mathrm{US}}=0.08$ & $\beta_{\mathrm{PRE}}^{\mathrm{CH}}=0.15^{* * *}$ & 0.08 \\
\hline H2: Differentiation advantages & $\beta_{\mathrm{DIF}}^{\mathrm{US}}=0.51^{* * *}$ & $\beta_{\mathrm{DIF}}^{\mathrm{CH}}=0.00$ & $-0.51 * * *$ \\
\hline H3: Cost advantages & $\beta_{\mathrm{COST}}^{\mathrm{US}}=0.18^{* * *}$ & $\beta_{\mathrm{COST}}^{\mathrm{CH}}=0.13 * * *$ & 0.05 \\
\hline
\end{tabular}

Dependent Variable: Number of Successful First-Mover Decisions

\begin{tabular}{lll}
\hline & & Country Difference \\
& U.S. & China \\
\hline H1: Preemptive advantages & $\beta_{\mathrm{PRE}}^{\mathrm{US}}=0.12$ & $\beta_{\mathrm{PRE}}^{\mathrm{CH}}=0.14 * *$ \\
H2: Differentiation advantages & $\beta_{\mathrm{DIF}}^{\mathrm{US}}=0.74^{* * *}$ & $\beta_{\mathrm{DIF}}^{\mathrm{CH}}=-0.05$ \\
H3: Cost advantages & $\beta_{\mathrm{COST}}^{\mathrm{US}}=0.32^{* * *}$ & $\beta_{\mathrm{COST}}^{\mathrm{CH}}=0.11^{* *}$ \\
\hline
\end{tabular}

Notes: According to H1, the U.S. preemption advantage coefficient will be significantly less than the corresponding Chinese coefficient. According to H2 and H3, the U.S. differentiation and cost advantage coefficients will be significantly greater than the corresponding Chinese coefficients.

$* * * p<.01 ; * * p<.05$. 
the two kinds of pioneer advantages (differentiation and cost advantages) that influence the entry decisions of U.S. entrepreneurs, only differentiation has a smaller impact on the entry decisions of Chinese entrepreneurs. This result supports $\mathrm{H} 2$.

\section{Pioneer Advantage Perceptions and the Number of Successful Entry Decisions}

In Table 5, the dependent variable is the number of successful first-mover decisions. In model 2 , the coefficients of both preemptive advantages $\left(\beta_{\mathrm{PRE}}^{\mathrm{US}}=.16, p<.01\right)$ and cost advantages $\left(\beta_{\mathrm{COST}}^{\mathrm{US}}=.19, p<.01\right)$ are positive and significant, while the coefficient of differentiation advantages is insignificant. The difference between the magnitude of the differentiation and cost coefficients is statistically significant $\left(\chi^{2}=5.20, p<.05\right)$. These results are consistent with those reported for model 2 in Table 4.

Similarly, in model 3 of Table 5, the main effects of the pioneer advantage variables are consistent with those reported in model 3 of Table 4. In the U.S. model, the regression coefficients for differentiation advantages $\left(\beta_{\mathrm{DIF}}^{\mathrm{US}}=.74, p<.01\right)$ and cost advantages $\left(\beta_{\mathrm{COST}}^{\mathrm{US}}=.32\right.$, $p<.01)$ are both positive and significant. As in Table 4, the difference between the magnitude of the differentiation and cost coefficients ( $\beta_{\mathrm{DIF}}^{\mathrm{US}}-\beta_{\mathrm{COST}}^{\mathrm{US}}$ ) is statistically significant $\left(\chi^{2}=5.21, p<.05\right)$. However, although perceptions of preemptive advantages have no significant relationship with the number of successful pioneer entry decisions made by U.S. entrepreneurs $\left(\beta_{\mathrm{PRE}}^{\mathrm{US}}=.12\right.$, $p>.10)$, the difference between the cost and preemptive advantage regression coefficients $\left(\beta_{\mathrm{COST}}^{\mathrm{US}}-\beta_{\mathrm{PRE}}^{\mathrm{US}}\right)$ is not significant $\left(\chi^{2}=1.96, p>.05\right)$.

In the Chinese sample, we find that perceptions of differentiation advantages have no impact on the number of successful first-mover decisions by Chinese entrepreneurs $\left(\beta_{\mathrm{DIF}}^{\mathrm{CH}}=\beta_{\mathrm{DIF}}^{\mathrm{US}}+\beta_{\mathrm{DIF}}^{\mathrm{INT}}=-.05, p>.10\right)$. However, these entry decisions are positively and significantly related with perceptions of preemptive advantage $\left(\beta_{\mathrm{PRE}}^{\mathrm{CH}}=\beta_{\mathrm{PRE}}^{\mathrm{US}}+\beta_{\mathrm{PRE}}^{\mathrm{INT}}=.14, p<.05\right)$ and cost advantages $\left(\beta_{\mathrm{COST}}^{\mathrm{CH}}=\beta_{\mathrm{COST}}^{\mathrm{US}}+\beta_{\mathrm{COST}}^{\mathrm{INT}}=.11, p<.05\right)$.

With regard to our research hypotheses, we find that, in contrast with Table 4, two of the three interaction terms are significant. The coefficient of China Dummy $\times$ Differentiation is negative and significant $\left(\beta_{\mathrm{DIF}}^{\mathrm{INT}}=-.80, p<.01\right)$. This result supports $\mathrm{H} 2$ (see Table 6). In addition, the coefficient of China Dummy $\times$ Cost is negative and significant $\left(\beta_{\mathrm{COST}}^{\mathrm{INT}}=-.22, p<.01\right)$, which supports H3. The sign of the coefficient of China Dummy $\times$ Preemption is positive $\left(\beta_{\mathrm{PRE}}^{\mathrm{INT}}=.02\right)$, which is consistent with $\mathrm{H} 1$, but the magnitude of this coefficient is not significantly different from zero. Thus, we cannot conclude that the relationship between preemption advantages and the number of firstmover advantages is stronger in the Chinese sample.

\section{Discussion}

In this paper, we have extended two recent countryspecific studies of pioneer advantage (Song et al., 2013; Zhao and Parry, 2012) by examining the following question: How do entrepreneurial perceptions of several theoretically important pioneer advantages impact the pioneer entry decisions made by U.S. and Chinese entrepreneurs? Our analysis, based on responses from 209 U.S. entrepreneurs and 302 Chinese entrepreneurs, provides evidence that the impact on early entry of variations in perceived pioneer differentiation advantages is stronger in the United States than in China. Similarly, perceived pioneer cost advantages also have a relatively stronger impact on successful early entry in the United States. Both of these findings are consistent with the argument that strong IP protections in the United States (relative to China) constitute an isolating mechanism that encourages early entry. In contrast, although we found that the coefficient linking perceptions of pioneer preemptive advantages with the number of successful first-mover decisions is significant in the Chinese sample and not in the U.S. sample, the difference between these coefficients is not significant.

\section{Research Implications}

Our findings extend existing discussions of market timing in several important ways. First, building on the resource-based view of the firm, we argued that the relative importance of differentiation advantages to potential first movers depends on the degree to which first movers can protect the IP that underlies those differentiation advantages. Consistent with this reasoning, our findings indicate that country-specific variations in the level of IP protection affect the strength of the relationship between perceived differentiation advantages and the number of pioneer entry decisions made by service entrepreneurs.

Second, we also argued that the relative importance of cost advantages to potential first movers depends on the degree to which first movers can protect the IP that underlies those cost advantages. Our findings reveal that the perception of pioneer cost advantages (1) does not increase the number of pioneer ventures started by U.S. entrepreneurs relative to their Chinese counterparts, but (2) does have a greater impact on the number of success- 
ful ventures started by U.S. entrepreneurs. One possible explanation for this result is that Chinese entrepreneurs overestimate the sustainability of pioneer cost advantages in China. This possibility should be explored in future research.

Third, we found that entrepreneurial perceptions of preemptive advantages were positively related with the number of successful first-mover entry decisions in China. This result is consistent with the argument that strong relationships (guanxi) can create a barrier to entry for companies that lack similar ties to relevant industry or supply chain partners (Luo, 2003; Park and Luo, 2001). In particular, our findings suggest that the importance of personal relationships in Chinese business affairs enhances the ability of Chinese entrepreneurs to secure preferential access to key resources.

Finally, our findings provide new insight into the market entry decisions of Chinese entrepreneurs. In their seminal cross-country study of first-mover advantages, Song et al. (2000; see also Song et al., 1999) examined the perceived importance of a variety of mechanisms that have been hypothesized to create advantages for pioneers. In their empirical analysis, the authors standardized each item to have a mean of zero and then tested the mean responses of managers from nine countries, including the United States and China. To clarify the differences between the results reported in these earlier studies and those reported here, Table 7 summarizes the mean responses of U.S. and Chinese managers in the Song et al. (2000) paper to items that are related to those used in the present study. As this table reveals, managers in both countries believed that at least one type of preemptive advantage could be an important source of competitive advantage. However, managers in both countries saw no benefit to key differentiation and cost advantages examined in previous studies. Importantly, these conclusions were based on comparisons of country-specific mean responses from managers in the United States, China, and seven other countries.

In contrast, the current study examines variations in the impact of perceived pioneering advantages on market entry decision within the United States and China. In particular, we used a three-step approach to assess the importance of pioneer advantages in each country. First, following Song et al. (2000), we used single-item measures to obtain the perceived importance ratings of a series of single-item measures of potential first-mover advantages. Second, we used confirmatory factor analysis to link these single-item measures to underlying constructs identified in the pioneer advantage literature. Third, we examined the relationship between the perceived importance of these constructs and the actual entry decisions of individual entrepreneurs. This procedure enables us to address the following question: To what extent do variations in the perceived importance of a pioneer advantage affect market entry behavior? As revealed in Table 8 , our results provide a stark contrast with those of Song et al. (2000). In particular, we find that entry decisions of U.S. service entrepreneurs are not influenced by the perceived importance of preemptive advantages, but are influenced by the perceived importance of cost and differentiation advantages. Moreover, the entry decisions of Chinese service entrepreneurs are not influenced by the perceived importance of preemptive or differentiation advantages, but are influenced by the perceived importance of cost advantages. These results

Table 7. Mean Importance Ratings from U.S. and Chinese Managers of Pioneer Advantage Mechanisms (Song et al., 2000)

\begin{tabular}{|c|c|c|}
\hline Item & U.S. & China \\
\hline \multicolumn{3}{|l|}{ Preemption advantages } \\
\hline First entrants can preempt raw material supplies. Later entrants get lower quality, higher priced raw materials. & $2.00^{\mathrm{a}}$ & .06 \\
\hline $\begin{array}{l}\text { First entrants can preempt equipment and location. Later entrants compete with more inferior equipment and in } \\
\text { unfavorable locations. }\end{array}$ & -.20 & $1.23^{\mathrm{a}}$ \\
\hline Pioneers are able to preempt the distribution channel. & $2.98^{\mathrm{a}}$ & -1.65 \\
\hline \multicolumn{3}{|l|}{ Differentiation advantages } \\
\hline Pioneers are perceived as technological leaders by customers. & -1.20 & .10 \\
\hline The quality and performance of a pioneer's products inhibits customer learning about competitors. & -.75 & -.08 \\
\hline $\begin{array}{l}\text { Pioneers have better brand images with buyers. Buyers purchase more pioneer products simply because buyers know them } \\
\text { first, use them and then stick with them. }\end{array}$ & -1.27 & -.90 \\
\hline \multicolumn{3}{|l|}{ Cost advantages } \\
\hline Pioneers will enjoy lower direct costs due to scale economy advantage. & -.16 & -.45 \\
\hline Pioneers tend to experience greater absolute cost savings (savings regardless of production scale). & -.20 & .21 \\
\hline
\end{tabular}

${ }^{a}$ Denotes item mean that is significantly different from zero at the $5 \%$ confidence level. 
Table 8. A Comparison of Conclusions from the Current Study with Those of (Song et al., 2000)

\begin{tabular}{|c|c|c|c|}
\hline & Song et al. (2000) & \multicolumn{2}{|c|}{ Current Study } \\
\hline esearch Question & $\begin{array}{l}\text { Among service firm executives in the United } \\
\text { States and China, are the average perceived } \\
\text { importance ratings of various pioneer } \\
\text { advantages significantly higher than zero? }\end{array}$ & $\begin{array}{l}\text { Among service entrepren } \\
\text { higher levels in the pe } \\
\text { advantages positively } \\
\text { pioneer entry decision }\end{array}$ & $\begin{array}{l}\text { tes and China, are } \\
\text { various pioneer } \\
\text { er number of } \\
\text { epreneurs? }\end{array}$ \\
\hline Country & United States & United States & China \\
\hline Preememption advantages ${ }^{\mathrm{a}}$ & $\mathrm{Yes}^{\mathrm{d}}$ & No & Yes \\
\hline Differentiation advantages $^{\mathrm{b}}$ & No & Yes & No \\
\hline Cost advantages $^{\mathrm{c}}$ & No & Yes & Yes \\
\hline \multicolumn{4}{|c|}{$\begin{array}{l}\text { Song et al. (2000) classified seven pioneer advantages as preemption advantages. This category included the three pioneer advantages that we have labeled } \\
\text { as differentiation advantages. } \\
\text { Song et al. (2000) classified seven pioneer advantages as behavioral advantages. This category included the three pioneer advantages that we have labeled } \\
\text { as differentiation advantages. } \\
\text { Song et al. (2000) classified three pioneer advantages as preemption advantages as economic pioneering advantages. This category included the two pioneer } \\
\text { advantages we labeled as cost advantages. } \\
\text { average rating across } 11 \text { other countries (including China). } \\
\text { an the Chinese sample, average ratings for one of the three statements common to both studies (these common items are listed in Table 7) were above the }\end{array}$} \\
\hline
\end{tabular}

raise important questions about the relationship between what entrepreneurs in particular and managers in general say is important and what they actually do. Thus one important direction for future research involves identifying the conditions under which an entrepreneur's statements about factors that influence his or her behavior are significantly correlated with the entrepreneur's behavior.

\section{Managerial Implications}

Our results have several important implications for U.S. and Chinese entrepreneurs. For U.S. entrepreneurs, our results provide guidance to managers in evaluating the importance of different kinds of pioneer entry advantages. In particular, among the three kinds of pioneer entry advantages examined in this paper, entrepreneurial perceptions of differentiation advantages had the strongest relation with the number of successful entry made by entrepreneurs in our U.S. sample. The strength of this relationship was significantly stronger than the relationship between entry decisions and the second important pioneer advantage, which was entrepreneurial perceptions of cost advantages. In contrast, entrepreneurial perceptions of preemptive advantages had no significant relationship with the number of successful entry decisions by U.S. entrepreneurs.

Our results raise several important questions for Chinese entrepreneurs. On the one hand, Chinese entrepreneurs are significantly more likely (relative to U.S. entrepreneurs) to introduce pioneering services, and even more likely to introduce successful pioneering services. On the other hand, the actual number of early entry deci- sions is not related with perceptions of differentiation. For this reason, Chinese entrepreneurs should be cautious about inferring the success of pioneering services from their perceptions of current differentiation advantages. However, our findings do suggest that, in China, perceptions of preemptive advantages and cost advantages are significantly related to the number of successful early entry decisions. This suggests that, in making market entry decisions, Chinese entrepreneurs should assess the potential cost benefits of early entry, as well as their ability to use personal connections to secure preferred access to key resources.

Finally, our results are relevant for U.S. entrepreneurs who may be considering early entry into a new Chinese market. Our results indicate that while perceptions of differentiation and cost advantages are related with successful entry decisions in the United States, those same variables are not related with successful entry decisions in China. Thus, U.S. entrepreneurs should be cautious about using their U.S. experiences to evaluate the potential return to early entry in China.

\section{Limitations}

Our conclusions must be qualified in several ways. First, because we defined a pioneer entrant as one of the first three firms to enter an industry, our results do not provide insights into the potential advantage of being first rather than second or third. Second, our measure of the number of successful pioneer entries captures the subjective performance evaluations of pioneer entrants within four years of entry. While we believe this measure is appro- 
priate given our focus on the subjective decision processes of service entrepreneurs, examining the relationships between perceptions of pioneer advantages and other measures of entrepreneurial performance is an important topic for future research.

Third, our study examined the market entry decisions of service entrepreneurs in five service industries. The work of Song et al. (1999) suggests that some of our results will not extend to manufacturing entrepreneurs. Fourth, we have argued that several of our results reflect differences between political, regulatory, and cultural characteristics of the U.S. and Chinese economies. However, it is also possible that the differences observed here reflect differences between developed and transitional economies, or between Western and Eastern cultures. Thus, future research should address the degree to which the results reported here generalize to manufacturing industries, as well as to other transitional economies and other Eastern cultures.

\section{Directions for Future Research}

In addition to the opportunities for future research mentioned above, several additional opportunities exist. First, in our study perceptions of preemptive advantages had no impact on the number of successful entry decisions by U.S. entrepreneurs. However, the items used to measure preemption advantages focus on the preemption of raw material supplies, service delivery channels, and service locations. This measure does not address the preemption of perceptual space or key market segments (Kerin et al., 1992; Song et al., 2000). Thus future research should examine the impact of these types of preemptive advantages on entrepreneurial entry decisions.

Second, our results indicate that, relative to U.S. firms, Chinese entrepreneurs are significantly more likely to successfully introduce pioneering services. One possible explanation for this result is that the U.S. entrepreneurs in our study compete in more established, mature industries, while the same industries in China are less mature because of the transitional nature of the Chinese economy. This explanation should be explored in future research.

Third, we have attributed the insignificance of differentiation advantages and lesser importance of cost advantages in China to the lack of adequate protections for IP and the underdevelopment (relative to the United States) of appropriate legal institutions. However, in the last few years, regulatory and legal reforms have been enacted that promise improvements in the protection of property rights (Sybert, 2008; Tan and Tan, 2005). Thus, future research should monitor the extent to which these reforms strengthen the relationship between the entry decisions of Chinese entrepreneurs and their perceptions of the differentiation and cost advantages of pioneer entry.

A final direction for future research concerns the relationship between a firm's existing resources and the timing of market entry decisions. Robinson, Fornell, and Sullivan (1992) concluded that pioneers do not necessarily have an absolute resource advantage over later entrants, but tend to have portfolios of skills and resources that are better suited to the challenges that confront early entrants. Mitchell (1989) found that the probability of entry into an emerging technical subfield depended in part on whether the firm had the specialized assets necessary for product development and distribution. Mitchell (1989) also concluded that, among incumbent firms in an industry, order-of-entry effects in emerging technical subfields depended on the entry timing of other incumbents, rather than all other entrants. He attributed this result to "the breadth of supporting capabilities possessed by incumbents" (p. 87). In a case study of the TV industry, Klepper and Simons (2000) found that firms with significant experience in radio manufacturing were more likely to enter the TV market relative to other firms, tended to enter the market earlier, and earn higher market shares. Given these results, future research should examine whether the relationship between perception of pioneer advantages and market entry is moderated by the possession of the skills and resources needed for early entry.

\section{References}

Alpert, F., and M. Kamins. 1994. Pioneer brand advantage and consumer behavior: A conceptual framework and propositional inventory. Journal of the Academy of Marketing Science 22 (3): 244-53.

Barney, J. 1991. Firm resources and sustained competitive advantage. Journal of Management Studies 17 (1): 99-120.

Barney, J., M. Wright, and D. J. Ketchen, Jr. 2001. The resource-based view of the firm: Ten years after 1991. Journal of Management 27 (6): $625-41$.

Brown, T. A. 2006. Confirmatory factor analysis for applied research. New York: The Guilford.

Carpenter, G. S., and K. Nakamoto. 1989. Consumer preference formation and pioneering advantage. Journal of Marketing Research 26 (3): 28598.

Cheung, G. W., and R. B. Rensvold. 2002. Evaluating goodness-of-fit indexes for testing measurement invariance. Structural Equation Modeling 9 (2): 233-55.

Comanor, W. S., and T. A. Wilson. 1979. Advertising and competition: A survey. Journal of Economic Literature 17 (June): 453-64.

Conner, K. R. 1991. A historical comparison of resource-based theory and five schools of thought within industrial organization economics: Do we have a new theory of the firm? Journal of Management 17 (1): 121-54.

Dierickx, I., and K. Cool. 1989. Asset stock accumulation and sustainability of competitive advantage. Management Science 35 (12): 1504-13. 
Dillman, D. A. 1978. Mail and telephone surveys: The total design method. New York: Wiley.

Douglas, S., and C. S. Craig. 1983. International marketing research. Englewood Cliffs, NJ: Prentice-Hall.

Fornell, C., W. T. Robinson, and B. Wernerfelt. 1985. Consumption experience and sales promotion expenditure. Management Science 31 (September): $1084-105$

Fowler, G. A. 2004. In China, ads that look the same. Far Eastern Economic Review 167 (17): 40-41.

Fung, H. G., X. E. Xu, and Q. Z. Zhang. 2007. On the financial performance of private enterprises in China. Journal of Developmental Entrepreneurship 12 (4): 399-414.

Hu, L., and P. M. Bentler. 1999. Cutoff criteria for fit indices in covariance structure analysis: Conventional criteria versus new alternatives. Structural Equation Modeling 6 (1): 1-55.

Kalyanaram, G., W. T. Robinson, and G. L. Urban. 1995. Order of market entry: Established empirical generalizations, and future research. Marketing Science 14 (3): 212-21.

Kerin, R. A., P. R. Varadarajan, and R. A. Peterson. 1992. First-mover advantage: A synthesis, conceptual framework, and research propositions. Journal of Marketing 56 (4): 33-52.

Klepper, S., and K. L. Simons. 2000. Dominance by birthright: Entry of prior radio producers and competitive ramifications in the U.S. television receiver industry. Strategic Management Journal 21 (10/11): 997 1016.

Li, J. J., L. Poppo, and K. Z. Zhou. 2008. Do managerial ties in China always produce value? Competition, uncertainty, and domestic vs. foreign firms. Strategic Management Journal 29 (4): 383-400.

Lieberman, M. B., and D. B. Montgomery. 1988. First-mover advantages. Strategic Management Journal 9 (5): 41-58.

Lieberman, M. B., and D. B. Montgomery. 1998. First-mover (dis)advantages: Retrospective and link with the resource-based view. Strategic Management Journal 19 (12): 1111-25.

Lilien, G. L., and E. Yoon. 1990. The timing of competitive market entry: An exploratory study of new industrial practices. Management Science 36 (5): $568-85$.

Lippman, S. A., and R. P. Rumelt. 1982. Uncertain imitability: An analysis of interfirm differences in efficiency under competition. Bell Journal of Economics 13 (2): 413-38.

Lockett, M. 1988. Culture and the problems of Chinese management. Organization Studies 9 (4): 475-96.

Luo, Y. D. 2003. Industrial dynamics and managerial networking in an emerging market: The case of China. Strategic Management Journal 24 (13): 1315-27.

Mahoney, J., and J. R. Pandian. 1992. The resource-based view within the conversation of strategic management. Strategic Management Journal 13 (5): $363-80$.

Mitchell, M. 1989. Whether and when? Probability and timing of incumbents' entry into emerging industrial subfields. Administrative Science Quarterly 34 (2): 208-30.

Mullen, M. R. 1995. Diagnosing measurement equivalence in crossnational research. Journal of International Business Studies 26 (3): $573-96$.

Nee, V. 1992. Organizational dynamics of market transition: Hybrid forms, property rights, and mixed economy in china. Administrative Science Quarterly 37 (1): 1-27.

Park, S., and Y. Luo. 2001. Guanxi and organizational dynamics: Organizational networking in Chinese firms. Strategic Management Journal 22 (5): 455-77.
Parry, M., and F. M. Bass. 1990. When to lead and when to follow? It depends. Marketing Letters 1 (November): 187-98.

Peng, M. W., and P. S. Heath. 1996. The growth of the firm in planned economies in transition: Institutions, organizations, and strategic choice. Academy of Management Review 21 (2): 492-534.

Peter, J. P. 1979. Reliability: A review of psychometric basics and recent marketing practices. Journal of Marketing Research 16 (February): 6-17.

Peteraf, M. A. 1993. The cornerstones of competitive advantage: A resource-based view. Strategic Management Journal 14 (3): 179-91.

Prescott, E. C., and M. B. Visscher. 1977. Sequential location among firms with foresight. Journal of Economics 8 (2): 378-93.

Robinson, W. T. 1988. Sources of market pioneer advantages: The case of industrial goods industries. Journal of Marketing Research 25 (February): $87-94$

Robinson, W. T., and C. Fornell. 1985. The sources of market pioneer advantages in the consumer goods industries. Journal of Marketing Research 22 (August): 297-304.

Robinson, W. T., C. Fornell, and M. W. Sullivan. 1992. Are market pioneers intrinsically stronger than later entrants? Strategic Management Journal 13 (November): 609-24.

Rumelt, R. P. 1984. Towards a strategic theory of the firm. In Competitive strategic management, ed. B. Lamb, 556-70. Englewood Cliffs, NJ: Prentice-Hall.

Schmalensee, R. 1982. Product differentiation advantages of pioneering brands. American Economic Review 72 (June): 349-65.

Schoenecker, T. S., and A. C. Cooper. 1998. The role of firm resources and organizational attributes in determining entry: A cross-industry study. Strategic Management Journal 19 (12): 1127-43.

Song, M., Y. L. Zhao, and C. A. Di Benedetto. 2013. Do perceived pioneering advantages lead to first-mover decisions in service industry. Journal of Business Research 66 (8): 1143-52.

Song, X. M., C. A. Di Benedetto, and L. Z. Song. 2000. Pioneering advantages in new service development: A multi-country study of managerial perceptions. Journal of Product Innovation Management 17 (5): 37892.

Song, X. M., C. A. Di Benedetto, and Y. L. Zhao. 1999. Pioneering advantages in manufacturing and service industries: Empirical evidence from nine countries. Strategic Management Journal 20 (9): 811-36.

Spence, A. M. 1979. Investment strategy and growth in a new market. Bell Journal of Economics 10 (1): 1-19.

Sybert, R. P. 2008. IP protection and counterfeiting in China. Intellectual Property \& Technology Law Journal 20 (7): 12-16.

Tan, J., and D. Tan. 2005. Environment-strategy co-evolution and co-alignment: A staged model of Chinese SOEs under transition. Strategic Management Journal 26 (2): 141-57.

Urban, G. L., T. Carter, S. Gaskin, and Z. Mucha. 1986. Market share rewards to pioneering brands: An empirical analysis and strategic implications. Management Science 32 (6): 645-59.

Wernerfelt, B. 1984. A resource-based view of the firm. Strategic Management Journal 5 (2): 171-80.

Williamson, O. E. 1979. Transaction-cost economics: The governance of contractual relations. Journal of Law and Economics 22 (2): 233-61.

Xin, K. R., and J. L. Pearce. 1996. Guanxi: Connections as substitutes for formal institutional support. Academy of Management Journal 39 (6): $1648-58$.

Zhao, Y. L., and M. E. Parry. 2012. Mental models and successful firstmover entry decisions: Empirical evidence from Chinese entrepreneurs. Journal of Product Innovation Management 29 (4): 590-607. 


\section{Appendix. Study Measures}

\section{Construct and Measures}

NFIRST $=$ number of first mover decisions over a four-year period

NSUCC $=$ number of success decisions over a four-year period

Preemptive Advantages (PRE) (Reliability $\alpha=.75$ for China; .81 for United States)

PREE1 Pioneers can preempt high quality raw material supplies

PREE2 Pioneers can preempt key service distribution/delivery channels

PREE3 Pioneers can preempt service locations. Late entrants have to compete with unfavorable locations

Differentiation Advantages (DIF) (Reliability $\alpha=.82$ for China; .71 for United States)

DIFF1 Pioneers are perceived as technological leaders by customers

DIFF2 Pioneers will have a better brand image in the industry

DIFF3 Pioneers can develop broader product lines than late entrants do

DIFF4 Pioneer's services are perceived to be higher quality by customers

Cost Advantages (COST) (Reliability $\alpha=.77$ for China; .78 for United States)

COST1 Pioneers will enjoy lower service delivery costs

COST2 Pioneers will enjoy lower direct costs due to scale economy advantage

COST3 Pioneers will have higher absolute cost savings 